\title{
Fatores que influenciam no processo da não autorização da doação de córneas no
}

\section{Estado do Maranhão}

\author{
Factors that influence the cornea donation non-authorization process in the State of Maranhão \\ Factores que influyen en el proceso de no autorización de donación de córnea en el Estado de
}

\section{Maranhão}

Recebido: 05/04/2021 | Revisado: 10/04/2021 | Aceito: 12/04/2021 | Publicado: 23/04/2021

Nubia Regina Pereira Da Silva

ORCID: https://orcid.org/0000-0003-1661-5555 Universidade CEUMA, Brasil

E-mail: nubiapsilva@hotmail.com

Rosane Mara Pontes de Oliveira

ORCID: https://orcid.org/0000-0002-2183-1423

Universidade Federal do Rio de Janeiro, Brasil

E-mail: romapope@gmail.com

Maria Giovana Borges Saidel

ORCID: https://orcid.org/0000-0002-3259-1760 Universidade CEUMA, Brasil

E-mail:mgsaidel@unicamp.br

Jose Márcio Soares Leite

ORCID: https://orcid.org/0000-0002-4943-2213 Universidade CEUMA, Brasil

E-mail: jmsoaresleite@gmail.com

Marcos Antônio Barbosa Pacheco

ORCID: https://orcid.org/0000-0002-3566-5462 Universidade CEUMA, Brasil

E-mail:mmmarco@terra.com.br

Claudia Barbastefano Monteiro

ORCID: https://orcid.org/0000-0002-3150-7424

Universidade Federal do Rio de Janeiro, Brasil E-mail: claudia.ipub@gmail.com

Cristina Maria Douat Loyola

ORCID: https://orcid.org/0000-0003-2824-6531 Universidade CEUMA, Brasil

E-mail: crisloyola@hotmail.com

\begin{abstract}
Resumo
Objetivo: compreender os fatores que influenciam no processo de não autorização da doação de córneas no Estado do Maranhão. Método: estudo qualitativo, analítico, pautado na teoria das representações sociais. Os dados foram coletados de julho a agosto de 2019. Resultados: os resultados apontaram para fatores negativos que influenciam a recusa familiar, como a discordância entre os responsáveis sobre a doação, a falta de discussão sobre o tema, o medo da burocracia atrasar a liberação do corpo morto, as convicções religiosas sobre a necessidade de manter os olhos íntegros após a morte, os sentimentos de desespero e responsabilidade para deliberar sobre o corpo entregue pela instituição hospitalar, a urgência de iniciar os rituais de luto, a falta de humanização na assistência anterior à morte e a suspeita de negligência médica. Dois fatores que poderiam influenciar para a doação são: identificar, para os familiares, o nome do receptor e discutir anteriormente a doação de órgãos. Conclusão: As dificuldades para a doação da córnea acontecem, em menor frequência, no período anterior ao óbito (desacordo entre familiares). As dificuldades que ocorrem, depois do óbito, são de natureza sociocultural. A urgência dos rituais de separação, a responsabilidade súbita pelo corpo morto, a não identificação do receptor e as representações sociais sobre os olhos do morto constituem-se em barreiras à doação. Como medidas, sugerem-se o fomento a campanhas de publicidade sobre a importância da doação e a implementação de equipe de apoio especializado para oferecer suporte às famílias de potenciais doadores.
\end{abstract}

Palavras-chave: Obtenção de órgãos e tecidos; Córnea; Doadores de tecidos.

\begin{abstract}
Objective: it is to comprehend the factors that influence in the process of not allowing the corneal donation in the Brazilian state of Maranhão. Methodology: it was a qualitative, analytical study, with 14 interviews analyzed through the theory of the thematic analysis, using the theory of social representations. Data were collected from July to August
\end{abstract}


2019. Results: the results pointed to negative factors that influence family refusal, such as the disagreement among those responsible for the donation, the lack of discussion on the topic, the fear of bureaucracy delaying the release of the body, religious beliefs about the necessity to keep one's eyes intact after death, feelings of despair and responsibility to deliberate about the body delivered by the hospital, the urgency on starting mourning rituals, the lack of humanization in assistance prior to death and the suspect of medical malpractice. Two factors that could positively influence the donation are: identifying the organ receiver's name for family members and discussing organ donation previously. Conclusion: difficulties in donating the cornea occur less frequently in the period before death (disagreement among family members). The difficulties that occur after death are mainly social and cultural. The urgency of the separation rituals, the sudden responsibility for the body, the non-identification of the recipient and the social representations in the eyes of the dead are barriers to donation. As measures, we suggest the promotion of advertising campaigns about the importance of donation and the implementation of a specialized support team to offer support to the families of potential donors.

Keywords: Procurement of organs and tissues; Cornea; Donors of tissues.

\section{Resumen}

Objetivo: comprender los factores que influyen en la no autorización para la donación de córnea en el estado de Maranhão. Método: estudio cualitativo, analítico, basado en la teoría de las representaciones sociales. Los datos fueron recolectados de julio a agosto de 2019. Resultados: los resultados apuntaron los factores negativos que influyen en el rechazo familiar, como el desacuerdo entre los responsables por la donación, la falta de discusión sobre el tema, el temor a retrasar la liberación del cuerpo por motivos burocráticos, convicciones religiosas sobre la necesidad de mantener los ojos intactos después de la muerte, sentimientos de desesperación y responsabilidad acerca de la deliberación sobre el cuerpo entregado por el hospital, la urgencia por iniciar rituales de duelo, la falta de humanización en la atención previa a la muerte y sospecha de negligencia médica. Dos factores que podrían favorecer la donación son: la divulgación del nombre del receptor a los miembros de la familia y la discusión previa sobre la donación de órganos. Conclusión: Las dificultades para donar la córnea ocurren con menos frecuencia en el período anterior a la muerte (es decir, desacuerdo entre los miembros de la familia). Las dificultades que ocurren después de la muerte son de naturaleza sociocultural. La urgencia de los rituales de separación, la responsabilidad repentina por el cadáver, la no identificación del receptor y las representaciones sociales sobre los ojos de los muertos son barreras para la donación. Como medidas, sugerimos la promoción de campañas publicitarias sobre la importancia de la donación y la implementación de un equipo de apoyo especializado para apoyar a las familias de los posibles donantes.

Palabras clave: Adquisición de órganos y tejidos; Córnea; Donantes de tejidos.

\section{Introdução}

As doenças que acometem a córnea, inclusive a ceratopatia bolhosa e a distrofia de Fuchs seguida de cerotocone são a terceira causa de cegueira no mundo, depois da catarata e do glaucoma. Estima-se que cerca de 53\% da população mundial tenha dificuldade em realizar o transplante de córnea, única possibilidade de reversão desta causa de cegueira (Gain et al., 2016).

Devido à menor taxa de rejeição, comparada a outros transplantes, a doação de córnea é uma das mais realizadas no mundo, com o melhor prognóstico em relação ao tempo de "vida do enxerto" (da Silva, Morato, Veneziano, \& Rodrigues, 2016).

No Brasil, o primeiro transplante de córnea foi realizado em 1958 e, desde então, esse tipo de procedimento é um dos mais executados no território brasileiro (Registro Brasileiro de Transplante - RBT, 2019).

No Maranhão, conforme dados Registro Brasileiro de Transplantes (RBT), em 2019, indicavam que havia 530 pacientes adultos e 36 pediátricos na lista de espera por uma córnea. No Brasil, nesse mesmo período, , o número de pacientes que aguardavam pelo transplante de córneas era de mais de dezoito mil pessoas (Registro Brasileiro de Transplante - RBT, 2019).

O Sistema Único de Saúde (SUS) é o responsável pela organização do sistema Nacional de transplantes (SNT) através da Política Nacional de Transplante de Órgãos e Tecidos (PNTOT). Nesta política, destacam-se a gratuidade da doação, os benefícios do ato de doar pela compaixão da ação e os princípios de segurança para doadores vivos, bem como o respeito pelos doadores falecidos. Estudos apontam que os principais motivos que influenciam para a não efetivação da doação 
de córneas são a recusa dos familiares, a contraindicação médica e a existência de problemas logísticos ou estruturais (Ministério da Saude Brasil, 2017).

A recusa familiar parece estar alimentada por inúmeros fatores, tais quais a falta de informação mais objetiva sobre o processo de doação e captação de órgãos e tecidos, o receio acerca do tráfico de órgãos, a mutilação do corpo, além dos processos burocráticos.(Ministério da Saude Brasil, 1997). É impactante, nesta discussão, o direito que o familiar detém sobre a autorização da doação, sendo a afirmativa ou negativa independentes da vontade anterior expressa pelo possível doador (Marinho, Conceição, \& Silva, 2018).

Nesse escopo, o tráfico de órgãos é considerado um crime global, de acordo com a análise de Castells (Castells, 2016). Na tentativa de coibir esta prática, médicos de todas as nações - preocupados com a situação - formaram um grupo, em 2008, para desenvolver estratégias de prevenção ao tráfico de órgãos e ao turismo de transplante, em Istambul, na Turquia. Essa reunião resultou na elaboração de um documento denominado "A Declaração de Istambul", que propôs um conjunto de princípios e propostas, que inclui equidade, justiça e respeito pela dignidade humana, destinados a promover os transplantes, com doador vivo ou falecido, de uma forma segura em todo o mundo (Oliveira, 2016).

Em 2001 a Lei 9.434, de 4 de fevereiro de 1997, para tratar da disposição de órgãos, tecidos, células e partes do corpo humano para fins de transplante e tratamento, sofreu alteração respeitava desejo expresso do doador. Com o decreto, a retirada de órgãos, tecidos, células e partes do corpo humano, após a morte, somente pode ser realizada com o consentimento livre e esclarecido da família do falecido. A autorização deve partir do cônjuge, do companheiro ou de parente consanguíneo, maior idade e juridicamente capaz, na linha reta ou colateral, até o segundo grau, e firmada em documento subscrito por duas testemunhas presentes à verificação da morte (D. O. da U. Brasil, 2018; Ministério da Saúde Brasil, 2001)

Segundo Foucault, a instituição hospitalar experimentou mudanças a partir do século XVII, deixando de ser um morredouro - onde se internavam "os perigosos" da sociedade, de modo a terem suas almas expiadas - para tornar-se uma instituição terapêutica, de intervenção no doente e na doença, com o propósito de salvar vidas. Nesse sentido, Foucault afirma que a disciplina é o conjunto de técnicas pelas quais os sistemas de poder vão ter por alvo e resultado, os indivíduos em sua singularidade. Destaca-se o poder de individualização, a respeito do qual o exame é o instrumento fundamental, é a vigilância permanente, que permite classificar e distribuir os indivíduos, de forma a julgá-los, medi-los, localizá-los e, em virtude disso, utilizá-los ao máximo. Portanto, isso se configura como a introdução dos mecanismos disciplinares no espaço confuso do hospital, que vai possibilitar a medicalização (Foucault, 1979).

Tendo a anatomia e a patologia como bases da clínica moderna, o discurso da biomedicina reorganizou o hospital moderno em torno da lógica do corpo humano como sede das doenças e da "imagem de guerra" contra o corpo doente (Cesar, 2004).

Esta permanente tensão acontece dentro do espaço hospitalar, que, de certa forma, torna-se proprietário do corpo do indivíduo. Sendo assim, durante a internação, o corpo vivo do paciente deixa de se submeter às decisões familiares - que são afastadas - e o poder de intervir, sobre o corpo vivo, é dos profissionais de saúde. Entretanto, quando acontece um óbito, o corpo retorna aos cuidados dos familiares, que, mesmo em um momento de intensa carga emocional, devem intervir e decidir sobre os trâmites necessários. Nessa ocasião, há poucas condições de decidir sobre a doação de órgãos e de tecidos (Miranda, 1987).

Os aspectos religiosos também desempenham relevante papel sobre a decisão de doar órgãos em uma sociedade. Historicamente, muitas religiões foram resistentes à ideia da doação de órgãos, por exemplo, nos dogmas do judaísmo, acredita-se que utilizar o corpo de um falecido significa adulterar a imagem de Deus. Na perspectiva dos protestantes, o corpo precisa estar intacto para o sucesso da ressurreição, portanto não se concorda com a visão de corpo mutilado (Lira, Pontes, Schirmer, \& Lima, 2012). 
A teoria das representações sociais pode ajudar a compreender a recusa de alguns católicos para a doação de órgão, o que contraria, inclusive, a orientação doutrinária da Igreja, que fomenta a doação (Rumsey, Hurford, \& Cole, 2003).

Dessa forma, a esperança é a base do pensamento primitivo e ela não permite que a racionalidade aflore.

A desautorização familiar para a doação de órgãos pode estar apoiada também na representação social e coletiva de séculos em relação à necessidade de a pessoa ter seus olhos, mesmo após a morte (Morera et al., 2015).

A pressão cultural sobre o discurso científico pode gerar interpretações variadas, as quais dificultam o entendimento sobre a determinação da morte encefálica, conceito científico que nem sempre é de domínio dos indivíduos leigos. Destarte, é preciso haver uma construção compreensiva, no âmbito do senso comum, sobre o coração ser um dos centros da vida, e a parada cardiorrespiratória ser determinante da morte.

Atualmente, a morte encefálica é determinante da morte biológica, ultrapassando a função do coração para a função cerebral como determinante da vida e da morte, que é constatada apenas através de exames específicos, cuja leitura é de difícil compreensão para um leigo. É perceptível que a família tem dificuldades para compreender a morte em um corpo que ainda respira, mesmo sob ventilação mecânica. Nesta situação, o tórax se expande como em uma respiração normal, a pele permanece rosada e quente, porém, clinicamente, é um corpo morto (Rodrigues Filho \& Junges, 2015).

Contudo, estudos têm destacado que o favorecimento do acesso à informação pelos familiares - através de entrevistas e palestras educativas objetivas - vem aumentando consideravelmente a aceitação e a discussão do tema em diversos ambientes, a exemplo de escolas, universidades, além de programas de rádio e televisão (Diaz, Ribeiro, \& Chaoubah, 2017).

Diante disto, a presente pesquisa objetivou compreender os fatores que influenciam no processo de não autorização da doação de córneas no Estado do Maranhão.

Considera-se que a influência do núcleo familiar determina, em grande parte, o desempenho dos indivíduos, tanto no nível pessoal quanto no coletivo, uma vez que este grupo social é o primeiro que oferece apoio e passa as informações sobre os riscos de morte ou não. Além disso, é a partir deste grupo social que o indivíduo recebe informações objetivas e subjetivas sobre a autorização ou a negação da doação de órgãos, bem como sobre a função maior do coração como determinante de se estar vivo ou morto.

\section{Metodologia}

Trata-se de estudo qualitativo, analítico, com 14 entrevistas realizadas à luz da análise temática, utilizando-se a teoria das representações sociais.

A partir da reflexão crítica de Moscovici (2000), utiliza-se a teoria das representações sociais, a qual considera que não há como separar o universo interno do indivíduo e o universo externo a este, pois ambos se complementam. Nesta ótica, a fim de analisar as representações sociais, selecionou-se a obra de arte intitulada $O$ Juízo Final, considerada uma das mais importantes obras do período Renascentista. Pintado por Michelangelo, entre 1535 e 1541, sob a forma de um afresco sobre parede, esse painel - que possui 13,7 m de largura por 12,2 m de altura - está localizado na Capela Sistina e ocupa integralmente a parede situada atrás do altar onde o papa celebra missas, o que demarca sua importância entre as demais obras do Vaticano, bem como determina a sua permanente visualização pelos fiéis. Segundo o artista, a pintura - inspirada em uma narrativa bíblica - expressa a raça humana e sua representação no dia do juízo final. Ressalta-se que, nesta expressão artística de mais 500 anos, as pessoas estão com seus olhos abertos e parecem enxergar bem, embora estejam mortos. O Cristo, parte central da cena retratada, é o juiz. A ressurreição dos mortos e os anjos tocando trombetas completam a composição (Lima, 2012). Além disso, ainda há uma referência à narração bíblica do evangelista João, capítulo 11, em que ocorre a ressureição de Lázaro. 
Os dados sociodemográficos e as informações médicas foram coletados no arquivo de um hospital de alta complexidade do Estado do Maranhão, com base no relatório que continha informações sobre as negativas familiares em relação a doações que poderiam ter sido realizadas por setenta e oito pacientes, segundo a Comissão Intra-Hospitalar de Doação de Órgãos e Tecidos para Transplante (CIHDOTT) do mesmo hospital no período de junho a agosto de 2019.

Foram incluídos os responsáveis legais de potenciais doadores de córneas que tiveram óbito constatado até seis horas após o evento ou que se encontravam em morte encefálica, constatada através de protocolo, por meio de busca em prontuário de doadores com registro de negativa familiar para a doação do tecido. Em seguida, os familiares foram convidados, por telefone, a participarem do estudo em data e local por eles escolhidos. Foram excluídos do estudo os familiares e responsáveis de doadores que apresentaram contraindicações, conforme RDC $\mathrm{n}^{\circ} 55$, de 11 de dezembro de 2015, e aqueles que se encontravam sem capacidade de comunicação no momento da entrevista.

Optou-se por definir o número de entrevistados através da inclusão progressiva (sem demarcar a priori o número de participantes), que foi interrompida pelo critério da saturação (Minayo, 2014), ou seja, quando as concepções, explicações e sentidos atribuídos pelos sujeitos começaram a ter uma regularidade de apresentação, sem haver novas inclusões. Com isso, foram consideradas 14 entrevistas.

Inicialmente, para a coleta de dados, utilizou-se a busca de dados em prontuários para o relato de recusa familiar para doação de córneas, observando-se a data e o motivo do óbito, bem como os dados do responsável pelo paciente. As entrevistas variaram entre 40 minutos a 4 horas.

A análise dos dados foi realizada a partir dos pressupostos da modalidade temática (Minayo, 2014), a fim de se descrever e compreender o processo das motivações que resultam na negativa de doação de córneas.

Para manter o anonimato dos participantes, as falas dos integrantes deste estudo foram indicadas pela letra "F", seguidas pelo número arábico que condiz com a ordem em que foram entrevistados.

A presente pesquisa foi aprovada pelo Comitê de Ética em Pesquisa através do Parecer Consubstanciado n 3.240.884, em 03 de abril de 2019.

\section{Resultados e Discussão}

\section{Caracterização do perfil dos participantes da pesquisa}

O grupo de entrevistados foi composto, em sua maioria, por mulheres solteiras, católicas, com idade variante entre 24 e 60 anos e, em relação à escolaridade, apresentavam Ensino Médio completo. Dentre elas, uma parte expressiva possuía parentesco em primeiro grau com o possível doador e demonstrava pouca ou nenhuma experiência anterior com doação de órgãos e tecidos.

Os dados proporcionaram uma organização formulada em duas categorias de análise sobre os influenciadores (positivos e negativos) para a doação, que serão apresentados em "por que não" e "por que sim".

\section{Porque não}

Os fatores que influenciam a doação de córneas podem ser divididos temporalmente entre os que acontecem antes da constatação do óbito - assim que este ocorre - e aqueles que ocorrem após o óbito. Foram listados doze argumentos dos entrevistados para não doar, e destes, apenas dois estão localizados na mesma hora do óbito.

Os núcleos de sentido que compuseram esta categoria foram: a discordância familiar entre doar ou não, a angústia pela perda diante da nova posse e responsabilidade sobre o destino do corpo morto, a demora para a liberação do corpo, o desconhecimento sobre a técnica de enucleação, a ansiedade em apressar os ritos de separação e luto, a falta de discussão familiar sobre o tema da doação, as representações sociais que constroem as oposições corpo íntegro/corpo cheio versus corpo 
mutilado/corpo oco, as religiões que proíbem a doação, o fato de alguém estar sozinho na hora desta decisão, a assistência pouco humanizada antes do óbito, a não identificação pública do receptor e a desobediência aos preceitos da religião católica, que orientam para haver doação.

A falta de discussão familiar anterior é um argumento forte para a dúvida sobre a doação, optando por recusar a realização do procedimento. "Olha, eu acredito que a minha mãe não aceitaria, meus irmãos também não iam aceitar [...]" (F7).

Outros fatores determinantes são a incapacidade de reassumir a responsabilidade sobre o corpo morto, a sensação de desespero instalada e o fato de se sentirem com pouco ou nenhum apoio emocional: "Eu estava sozinha na hora do óbito. Eu acho que foi o desespero no momento. Não foi falta de conhecimento, foi desespero mesmo. [...] Acho que se tivessem conversado com a gente antes da morte, eu teria doado. Na hora do desespero, não há espaço para pensar sobre isso" (F2).

A vivência do abandono e a falta de humanização na assistência prestada pelos profissionais de saúde, - apontando para a ausência de empatia e de respeito com a morte e o morrer - além da postergação dos atendimentos e dos esclarecimentos solicitados foram queixas recorrentes entre os entrevistados. Ressalta-se que o veículo utilizado para remoção dos corpos, popularmente conhecido como "rabecão", tem impacto negativo na percepção dos familiares, pois remete ao abandono e desrespeito ao corpo morto.

"Isso foi triste, né? Porque a gente a viu sendo levada no rabecão, assim em outros olhos parecia uma pessoa encontrada." (F3). "A equipe não explica o procedimento antes, só na hora de fazer a retirada do órgão, falta mais atenção por parte da equipe" (F9).

A revolta pela morte - advinda da esperança de um "milagre" de uma possível recuperação e da suspeita de negligência médica, com informação de óbito pelo telefone - forma a percepção, por parte dos familiares, de que não houve humanização no cuidado.

O desconhecimento sobre os procedimentos envolvidos na enucleação e a suposição de que a retirada da córnea pode retardar a liberação do corpo morto, para os rituais sociais e religiosos de separação e luto, reafirmam a opção pela recusa: "[...] foi negada a doação por parte da família quando eles souberam que ia demorar mais algum tempo para poder fazer todos os procedimentos [...] de retirada de órgãos” (F9). "[...] acreditei que isso causaria a violação do corpo do meu pai $[\ldots] "(\mathrm{~F} 8)$.

A não profanação física do corpo - e a angústia quando isso acontece - perpassa a necessidade da permanência imaginária de uma integridade física, inscrita em muitas representações sociais, baseadas em possíveis encontros, religiosos ou não, após a morte, que exigem um corpo inviolado e com olhos abertos. Essa convicção dificulta a doação: "[...] do hospital, eи liguei para a mãe dela e ela disse que por tudo de mais sagrado neste mundo, traga minha filha completa do jeito que ela saiu daqui" (F4).

Dos entrevistados, apenas um era membro da Igreja de Jesus Cristo dos Santos dos Últimos Dias, a qual não permite a doação de órgãos. As falas sobre a falta de humanização da assistência - concretizadas em não prestar esclarecimentos sobre os procedimentos -, a revolta e a suspeita de negligência médica foram fatores que interferiram na abordagem sobre doação de córneas, conforme as declarações a seguir: "Fiquei muito revoltada. Eu não ia aceitar ele ir para cirurgia sem exames. Acho que foi negligência médica” (F10). "[...] quando a pessoa falece na religião dela [mãe do entrevistado] não é autorizado [...] nenhum tipo de retirada de órgãos ou tecidos ou qualquer parte do corpo" (F5).

A maior parte dos relatos aponta para o fato de que a religião não influenciaria na decisão sobre a doação e, embora alguns tenham se declarado católicos e com conhecimento de que a religião prega a doação através do amor ao próximo, os depoentes optaram por negar a doação de córneas. 


\section{Porque sim}

Os fatos que protegem a doação de córnea não são objeto específico deste estudo, porém servem como uma reflexão oposta, sobretudo porque as duas justificativas para autorizar a doação remetem ao tempo anterior ao óbito. Assim, o que acontece antes influencia diretamente o que acontecerá depois.

As justificativas que protegem a doação de córneas estão ligadas à qualidade da assistência recebida antes do óbito, à carga de humanização percebida e à compreensão mais objetiva do que quer dizer morte encefálica (ME). Em relação a este último aspecto, a aparência e o conteúdo são vistos como contraditórios, pois, na concepção leiga, há dominância do coração na manutenção da vida.

A humanização - que remete ao fato de sentir-se acolhido e bem atendido por todos os membros de uma equipe multiprofissional - e a sensação de que o óbito foi um insucesso do grande esforço realizado pela equipe de saúde, que lutou para a reversão do quadro de gravidade daquele paciente, são vivências que favorecem a doação: "Ele foi tratado super bem, da maneira melhor possivel. Sobre o cuidado da equipe para conosco não há reclamação alguma” (F7).

A compreensão sobre o conceito de morte encefálica é um fator de proteção para a doação, pois, quando o participante conhece o diagnóstico e entende que a ausência de atividades cerebrais representa, conceitualmente, a morte do corpo, há mais clareza sobre o processo sobre o qual se passou. "Sei que a equipe fez tudo o que podia fazer" (F7).

A experiência com doação na família, com pessoas próximas ou histórias compartilhadas favorece a autorização. Além disso, o temor por um dia estar na fila de transplantes também reforça o comportamento positivo para a doação. Sendo assim, doar pode ser entendido como "manter o doador vivo no corpo de outra pessoa", e esta representação simbólica - que indica permanência - apareceu em algumas falas, embora a legislação brasileira não permita a identificação daquele que doa. "Ela poderia ser uma doadora e isso me deixou duplamente triste. Por ela ter falecido e não ter ajudado outra pessoa" (F11).

A consciência da gravidade do caso, cuja abordagem poderia ser iniciada pela equipe de saúde, talvez pudesse levar os participantes a adotarem uma postura menos defensiva em relação à futura perda e ao luto, permitindo, assim, que os familiares iniciassem a discussão sobre a doação de córnea antes do óbito, pois, no momento da morte, esta discussão fica muito angustiante e aflitiva, especialmente quando o familiar se encontra sozinho para decidir os destinos do corpo morto. "Eu concordo com a doação de órgãos e tecidos, mas acho que deveria haver uma orientação antes do óbito, desde a internação. Na hora do óbito é complicado falar sobre" (F6).

Compreender a gravidade clínica que antecede a morte e ter compartilhado outros momentos de discussão sobre doação de tecidos foram fatores de proteção para a doação.

Os principais obstáculos para efetivar a doação foram o desejo expresso, em vida, de não doar e a recusa dos próprios familiares diante da morte concreta.

Ademais, outros fatores foram destacados neste estudo: o tempo decorrido para a devolução do corpo morto à família para os rituais de separação, o desconhecimento sobre o diagnóstico de morte encefálica e as orientações contidas nas religiões (De Oliveira Bertasi et al., 2019). As dificuldades de compreensão sobre a morte, bem como a aceitação da terminalidade, expressaram uma espécie de força, uma vez que o hospital exerce domínio sobre o corpo vivo, mas transfere esta responsabilidade à família a partir do óbito. Na fala dos entrevistados, é nítida a quebra precoce da ruptura dos vínculos de responsabilidade familiar, havendo despreparo dos participantes para o momento do óbito.

Na presente pesquisa, a religião não foi uma barreira para a autorização do procedimento de doação de córneas, com exceção de um entrevistado, que se declarou integrante da Igreja de Jesus Cristo dos Santos dos Últimos Dias. Os demais entrevistados relataram que a religião não impedia o processo de autorização da doação de órgãos e tecidos. Mesmo os praticantes da religião protestante destacaram a importância da doação. 
Em estudo sobre a percepção dos familiares na doação de órgãos e tecidos, a maioria católica prevaleceu entre os familiares, corroborando com os dados da presente pesquisa (Santos, Santos, Lira, \& Moura, 2019). Este dado pode estar relacionado com o perfil religioso do Maranhão, de maioria católica.

A discussão acerca das crenças religiosas possibilita afirmar que, quanto mais fortes são as convicções religiosas de um grupo social, menores são as chances de partilhar uma parte do corpo, ainda que esta atitude, dentro da religião Católica, não seja coerente com a instrução normativa do Vaticano, nem com a orientação de amor ao próximo. Portanto, autorizar, proibir, punir, obedecer e desobedecer também são comportamentos instruídos por representações coletivas sobre a vida e a morte com alguma independência dos preceitos religiosos (Neto, 2010).

A falta de conhecimento que dificulta o processo de doação é evidenciada em um estudo realizado com 57 graduandos de enfermagem sobre doação de órgãos e o desejo de ser ou não doador. Participaram deste estudo graduandos do quinto, sexto, sétimo e oitavo semestres da Universidade Católica de Brasília, destacando-se que mais da metade dos entrevistados não possuía conhecimentos sobre as leis, as diretrizes e os procedimentos que são realizados antes, durante e após a autorização da doação de órgãos e tecidos. Destacou-se, por outro lado, o medo que os participantes expressaram sobre o comércio de órgãos: tendo em vista essa preocupação, o número de doadores tende a manter os limites inferiores às demandas de pessoas necessitadas de órgãos e tecidos no Brasil e no mundo Além disso, reitera-se que o conhecimento sobre doação de órgãos é insuficiente em muitos grupos, inclusive dentro do ambiente universitário, onde há acentuada resistência para doação, o que revela a urgência de discussões e esclarecimentos sobre a temática em diversos espaços do cotidiano (Bispo, Lima, \& Oliveira, 2016).

A postura de quem comunica a morte é importante para obter êxito na doação de órgãos e tecidos. Levando isso em consideração, é preciso ter preparo para fazer esse tipo de contato, sobretudo pelo telefone, pois, quando se realiza uma lig ação para um familiar que possui um paciente hospitalizado em estado grave, solicitando o comparecimento da família ao hospital, presume-se o anúncio do óbito. A comunicação da morte é um momento crítico, com vivência de desespero pela família, exigindo empatia, compreensão, solidariedade, além de suporte emocional (Hirschheimer, 2016).

Neste momento, a autorização familiar é influenciada pelo tratamento que foi recebido pelo paciente (Castro, Costa, \& Pissaia, 2018). A presente pesquisa confirma isso ao identificar, nas falas dos participantes, a importância de sentir-se acolhido pela equipe assistencial naquele momento de dor. Entre os católicos, a recusa para a doação de órgãos também está orientada pelas representações sociais coletivas sobre evitar um corpo mutilado, ferido, sem estética diante da necessidade de harmonia para comparecer ao Juízo final (Passarinho, Gonçalves, \& Garrafa, 2003). A presente pesquisa não destacou, explicitamente, o receio do tráfico de órgãos em falas dos participantes.

Para reduzir os impactos da recusa, um estudo sobre o consentimento dos familiares para a doação de órgãos e tecidos - que investigou 12 familiares de potenciais doadores, entre março de 2012 a junho de 2013, no Hospital de Clínicas da Universidade Estadual de Campinas - identificou que o apoio emocional, por parte da equipe que presta assistência em todas as etapas da abordagem, favoreceu a aceitação para doação (Fernandes, Bittencourt, \& Boin, 2015). Observou-se, neste estudo, que as famílias que relataram ter um atendimento considerado humanizado, por parte da equipe de saúde, tendem a autorizar a doação de órgãos em um próximo momento.

\section{Conclusão}

A falta de conhecimento sobre o tema e a ausência de discussão prévia sobre ser ou não doador de órgãos e tecidos são os principais motivos para a recusa familiar no processo de doação de órgãos e tecidos. A religião não apresentou, neste estudo, influência dominante para recusa, nem para efetivar a doação como um ato de amor ao próximo. 
Um importante fator de risco sobre a negativa é a falta de humanização na assistência médica, que inclui pouco acolhimento à família por todos os profissionais do hospital. Os aspectos culturais - em relação a manter o corpo íntegro e o receio em desrespeitar o corpo morto - fortalecem e confirmam a recusa da família. Sendo assim, as representações sociais permanecerão orientando a recusa para a doação, apoiando-se na percepção sobre a necessidade de manter a integridade do corpo após a morte, destacando-se, neste cenário religioso, a cena do juízo final aqui estudada.

A assistência de má qualidade recebida antes do óbito, a falta de compreensão sobre a morte cerebral, como marcador biológico definitivo da morte, a expectativa de reversão do quadro de morte e o desconhecimento sobre a técnica de retirada da córnea também são fatores impeditivos da doação.

Diante do exposto, seria igualmente importante aproximar a responsabilidade progressiva dos familiares no manejo do paciente internado, em estado grave ou terminal, de modo a diminuir o choque da responsabilidade sobre o corpo a partir do óbito.

Sugere-se, como medida para modificação do cenário atual, a implementação de uma equipe de apoio especializado com a participação de profissionais do serviço social, da psicologia e da enfermagem, para a abordagem emocional da família no momento concreto da perda, ou seja, diante do corpo morto.

É relevante, dentro do escopo aludido, um enfoque mais acentuado das campanhas de mídia, tornando claro o procedimento de retirada dos tecidos e o impacto positivo desta doação na vida do transplantado. Estas campanhas deveriam focar, além disso, nos aspectos legais da doação, de modo a elucidar um possível receio quanto ao tráfico de órgãos, esclarecendo, ainda, que as leis brasileiras impedem aos familiares conhecer ou escolher o receptor.

\section{Referências}

Bispo, C. R., Lima, J. C., \& Oliveira, M. L. C. de. (2016). Doação de órgãos: uma perspectiva de graduandos de enfermagem. Rev. bioét. (Impr.), $24(2)$, 386. http://search.ebscohost.com/login. aspx $?$ direct=true $\&$ AuthType $=$ sso \&db=edssci\&AN=edssci.S1983.80422016000200386\&lang=es $\&$ site $=$ eds - live $\&$ scope $=$ cite

Brasil, D. O. da U. Decreto ${ }^{\circ} 9.175$ de 18 de outubro de 2017 (2018).

Brasil, Ministério da Saude. LEI n ${ }^{\circ}$ 9.434, de 04 de fevereiro de 1997 (1997).

Brasil, Ministério da Saude. Portaria de consolidação No 04, de 28 de setembro de 2017. (2017). http://bvsms.saude.gov.br/bvs/saudelegi s/gm/2017/prc0003_03_10_2017.html

Brasil, Ministério da Saúde. LEI N 10.211, de 23 de Março de 2001 (2001). http://www.planalto.gov.br/CCIVIL_03/Leis/LEIS_2001/L10211.htm

Castells, M. (2016). A sociedade em rede:a era da informação: economia, sociedade e cultura. In Paz e Terra (Org.), Trafico de orgãos: uma análise do fenômeno sob a perspectiva da legislação brasileira (10 ed, p. 630). São Paulo.

Castro, M. De, Costa, A. E. K. da, \& Pissaia, L. F. (2018). Percepção Da Família Dos Doadores No Processo De Doação De Órgãos. Revista Destaques Acadêmicos, 10(3), 180-189. https://doi.org/10.22410/issn.2176-3070.v10i3a2018.1956

Cesar, M. R. de A. (2004). Da escola disciplinar a pedagogia do controle. http://repositorio.unicamp.br/jspui/handle/REPOSIP/252663

da Silva, R. E., Morato, R. M., Veneziano, R. T. S., \& Rodrigues, F. W. (2016). Epidemiological profile of west center cornea donors. Revista Brasileira de Oftalmologia, 75(4), 274-278. https://doi.org/10.5935/0034-7280.20160055

De Oliveira Bertasi, R. A., De Oliveira Bertasi, T. G., Reigada, C. P. H., Ricetto, E., De Oliveira Bonfim, K., Santos, L. A., \& Hirano, E. S. (2019). Profile of potential organ donors and factors related to donation and non-donation of organs in an organ procurement service. Revista do Colegio Brasileiro de Cirurgioes, 46(3), 1-8. https://doi.org/10.1590/0100-6991e-201922180

Diaz, F. B. B. de S., Ribeiro, L., \& Chaoubah, A. (2017). Análise dos fatores que influenciam o processo de doação de córneas . Revista de Enfermagem UFPE on line, 11(4). https://doi.org/10.5205/reuol.9763-85423-1-SM.1104201718

Fernandes, M. E. N., Bittencourt, Z. Z. L. de C., \& Boin, I. de F. S. F. (2015). Experiencing organ donation: Feelings of relatives after consent. Revista LatinoAmericana de Enfermagem, 23(5), 895-901. https://doi.org/10.1590/0104-1169.0486.2629

Ferreirinha, I. M. N., \& Raitz, T. R. (2010). As relações de poder em Michel Foucault: reflexões teóricas. Revista de Administração Pública, 44(2), 367-383. https://doi.org/10.1590/s0034-76122010000200008

Foucault, M. (1979). Microfisca do poder. (E. Graal, Org.). 
Research, Society and Development, v. 10, n. 4, e56210414664, 2021

(CC BY 4.0) | ISSN 2525-3409 | DOI: http://dx.doi.org/10.33448/rsd-v10i4.14664

Gain, P., Jullienne, R., He, Z., Aldossary, M., Acquart, S., Cognasse, F., \& Thuret, G. (2016). Global survey of corneal tran splantation and eye banking. JAMA Ophthalmology, 134(2), 167-173. https://doi.org/10.1001/jamaophthalmol.2015.4776

Hirschheimer, M. R. (2016). Morte encefálica e doação de órgãos e tecidos. Resideência Pediátrica, 6(1), 29-45.

Lima, L. A. (2012). Apocalipse como literatura: um estudo sobre a importância da análise da arte literária em apocalipse 12-13.

Lira, G. G., Pontes, C. M., Schirmer, J., \& Lima, L. S. de. (2012). Ponderações de familiares sobre a decisão de recusar a doação de órgãos*. Acta Paul Enferm., 25(2), 140-145.

Marinho, C. L. A., Conceição, A. I. C. de C., \& Silva, R. S. da. (2018). Causas de recusa familiar na doação de órgãos e tecidos. Revista Enfermagem Contemporânea, 7(1), 34. https://doi.org/10.17267/2317-3378rec.v7i1.2008

Minayo, M. C. de S. (2014). O desafio do conhecimento: pesquisa qualitativa em saúde. (Hucitec, Org.) (14a ed).

Miranda, C. M. L. (1987). Os doce(i)s corpos do hospital: as enfermeiras e o poder institucional na estrutura hospitalar.

Morera, J. A. C., Padilha, M. I., Silva, D. G. V. da, \& Sapag, J. (2015). Theoretical and Methodological Aspects of Social Representations. Texto \& Contexto Enfermagem, 24(4), 1157-1165. https://doi.org/10.1590/0104-0707201500003440014

Moscovici, S. (2015). Representações sociais: investigações em psicologia social. (E. Vozes, Org.) (11a ed). Petropolis.

Neto, Y. C. (2010). Morte encefálica: Cinquenta anos além do coma profundo. Revista Brasileira de Saude Materno Infantil, 10(SUPPL. 2), 355-361. https://doi.org/10.1590/s1519-38292010000600013

Oliveira, B. M. S. de. (2016). Interpretação da Declaração de Istambul sobre o Tráfico de Órgãos e Turismo de Transplante.

Passarinho, L. E. V., Gonçalves, M. P., \& Garrafa, V. (2003). Estudo bioético dos transplantes renais com doadores vivos não-parentes no Brasil: a ineficácia da legislação no impedimento do comércio de órgãos. Revista da Associação Médica Brasileira, 49(4), 382-388. https://doi.org/10.1590/s010442302003000400028

Registro Brasileiro de Transplante - RBT. (2019). Dimensionamento dos Transplantes no Brasil e em cada estado (2012-2019). Veiculo oficial da Associação Brasileira de Transplante de Orgãos - ABTO, XXV(4), 1-88.

Rodrigues Filho, E. M., \& Junges, J. R. (2015). Morte encefálica: uma discussão encerrada? Revista Bioética, 23(3), 485-494. https://doi.org/10.1590/198380422015233085

Rumsey, S., Hurford, D. P., \& Cole, A. K. (2003). Influence of knowledge and religiousness on attitudes toward organ donation. Transplantation Proceedings, 35(8), 2845-2850. https://doi.org/10.1016/j.transproceed.2003.10.078

Santos, J. I. R. dos, Santos, A. D. B. dos, Lira, G. G., \& Moura, L. T. R. de. (2019). Percepção de familiares sobre a doação de órgãos e tecidos. Rev. enferm. UFPE on line, 13(3), 578-586. 